\title{
Эколого-ценотическая характеристика флоры сосняков памятника природы «Медведский бор» (Кировская область)
}

\section{Ecological-coenotical characteristic of flora of pine forests of the natural monument «Medvedskij Bor» (Kirov region)}

\author{
Пересторонина О. Н., Шабалкина С. В., Савиных Н. П. \\ Perestoronina O. N., Shabalkina S. V., Savinykh N. P. \\ Вятский государственный университет, г. Киров, Россия. E-mail: Nasturtium2017@yandex.ru \\ Vyatka State University, Kirov, Russia
}

\begin{abstract}
Реферат. Описано видовое разнообразие сосняков зеленомошных одновозрастных (с формулой 10С) и с двумя ярусами Pinus sylvestris L. в древостое (формулы 7C3C, 8C2C, 5C5C, 6C4C) памятника природы «Медведский бор». Выявленная флора распределена по 9 эколого-ценотическим группам. Преобладают растения боровой и бореальной групп, что подтверждает наличие в прошлом более сухих боров и их трансформацию в зональные темнохвойные леса.
\end{abstract}

Ключевые слова. Биоразнообразие, памятник природы «Медведский бор», растительность, сосновый лес, флора, эколого-ценотическая группа.

Summary. The species diversity of pine forests of the same age (with formula 10P) and different age (formulas 7P3P, 8P2P, 5P5P, 6P4PC) of nature monument "Medvedskij Bor" is described. The identified flora is distributed on 9 ecological-coenotical groups. Plants of pine-forest and boreal groups prevail, which confirms the presence in the past of drier pine forests and their transformation into zonal dark coniferous forests.

Key words. Biodiversity, ecological-coenotical group, flora, nature monument "Medvedskij Bor", pine forest, vegetation.

В Нолинском районе у пос. Медведок находится памятник природы «Медведский бор» (ПП) - уникальная территория в пределах не только Кировской области, но и северо-востока России. Это крупный лесной массив площадью 6 921,05 га (55 кварталов), реликтовое сообщество ксеротермической эпохи послеледникового времени с цепью озер карстового происхождения. Он расположен на материковых песчаных дюнах по второй и третьей надпойменным террасам левого берега р. Вятки (Соловьев, 1986).

Изучение флоры и растительности Медведского бора начато сотрудниками Вятского государственного университета с 2001 г. и продолжается по настоящее время. Исследования показали: сочетания фитоценозов в бору разнообразны, что обусловлено особенностями рельефа данной местности. В настоящее время выделяются следующие группы растительных ассоциаций: сосняк-лишайниковый, сосняк травяной, сосняк зеленомошно-лишайниковый, сосняк зеленомошный, сосняк сложный, елово-сосняк зеленомошный, елово-сосняк зеленомошно-лишайниковый, ельник зеленомошный, липняк c Acer platanoides L. в подросте, липняк неморально-травяной, осино-березняк травяной, осино-березняк неморально-разнотравный, осино-березняк сфагновый (Киселёва и др., 2005; Савиных и др., 2006, 2012; Пересторонина и др., 2017)).

На территории памятника природы преобладают монодоминантные сосняки, распределенные по пяти группам ассоциаций. В составе подроста сложных боров встречается много растений Tilia cordata Mill. вегетативного происхождения, в травяно-кустарничковом ярусе присутствуют виды неморального комплекса: Polygonatum multiflorum (L.) All., Convallaria majalis L. и др. 
Наиболее представлена в Медведском бору группа сосняков зеленомошных, которая объединяет самое большое число ассоциаций. Среди них преобладают чистые сосняки брусничники и сосняки вейниково-брусничные, реже встречаются сосняки: плауново-брусничные, ландышевые, бруснично-черничные, черничные, бруснично-купеновые и др. Единично отмечены сосняки вейниково-орляковые. Чистые сосняки зеленомошные с зарослями кустарников Juniperus communis L. и Chamaecytisus ruthenicus (Fisch. ex Woloszcz.) Klaskova приурочены к средним частям склонов дюн.

В сосняке травяном рассеянно встречаются степные виды растений - Pulsatilla patens (L.) Mill., Veronica spicata L., Potentilla humifusa Willd. ex Schlecht., Centaurea sumensis Kalen.; представители неморального комплекса - P. multiflorum и C. majalis, таежный вид - Arctostaphylos uva-ursi (L.) Spreng. Bсе отмеченные растения произрастают среди мохово-лишайникового покрова. В ассоциациях сосняков зеленомошно-лишайниковых хорошо выражен подлесок из J. communis и Ch. ruthenicus. В травостое также встречаются вышеупомянутые виды степных трав. Из сосняков лишайниковых наиболее интересны ассоциации с кустарниками J. communis и Ch. ruthenicus, с Gypsophila paniculata L. в травянисто-кустарничковом ярусе.

Данная работа посвящена анализу спектра эколого-ценотических групп (ЭЦГ) флоры сосняков зеленомошных редкостойных (с формулой 10 C) и с двумя ярусами Pinus sylvestris L. в древостое (формулы 7С 3С, 8C2C, 5C5C, 6C4C) ПП «Медведский бор». Материалом для этого стали полные геоботанические описания, выполненные по общепринятым методикам (Полевая геоботаника, 1964, 1972). При распределении видов растений по эколого-ценотическим группам использовали подходы О. В. Смирновой и Л. Б. Заугольновой (Оценка и сохранение..., 2000). Согласно этому выделяем следующие группы: водно-болотная (Wt); влажно-луговая или пойменная (MFr); сухих лугов (MDr); неморальная (Nm); бореальная (Br); боровая (Pn); неморально-опушечная (ExEd); олиготрофная $(\mathrm{Olg})$; бореально-опушечная $(\mathrm{BrH})$; псаммофитно-травяная или сухих песков (PsTr); ковыльниковая или лугово-степная (Kov).

Сосняки зеленомошные с формулой 10С имеют возраст 128-130 лет. Полнота насаждений варьирует от 0,5 до 0,7, сомкнутость крон - 0,5-0,6. P. sylvestris высотой 23-25 м при диаметре ствола в среднем от 36 до 39 см. В пологе присутствуют Picea x fennica (Regel) Kom. и Betula pendula Roth. В возобновлении леса участвуют P. sylvestris, P. х fennica, B. pendula, Quercus robur L. Сомкнутость полога подлеска невысокая $-3-5 \%$, он представлен пятью видами (табл. 1) из боровой, бореальной и сухих песков ЭЦГ. Проективное покрытие травяно-кустарничкового яруса варьирует от 40 до 70 \%, он сложен 27 видами растений, среди которых преобладают представители боровой и бореальной ЭЦГ (табл. 2). Мохово-лишайниковый ярус образован 6 видами зеленых мхов и двумя видами лишайников. Доминирует в нем Pleurozium schreberi (Brid.) Mitt. (20-65 \%), несколько меньше Dicranum scoparium Hedw. и Dicranum polysetum Sw. (табл. 1).

Разновозрастные боры имеют возраст P. sylvestris от 50 до 120 лет. Полнота насаждений варьирует от 0,5 до 0,7 . Сосняк с формулой 7С 3 и имеет 3 класс бонитета, сомкнутость крон 0,5. Возраст P. sylvestris 113 и 73 года соответственно породному составу. Древостой высотой от 18 до 24 м при диаметре стволов от 24 до 45 см. Подлесок разреженный, сомкнутость полога - 10 \%. Травяно-кустарничковый ярус имеет проективное покрытие 40 \% и представлен 26 видами. Преобладает в нем Vaccinium vitis-idaea L., пятнами встречаются Calamagrostis epigeios (L.) Roth и C. majalis. Растения этого яруса распределены по следующим ЭЦГ: $\mathrm{Pn}-14$ видов, $\mathrm{Br}-3, \mathrm{BrH}-1, \mathrm{Nm}-2, \mathrm{ExEd}-1, \mathrm{MDr}-4, \mathrm{Kov}-1$. Проективное покрытие мохово-лишайникового яруса составляет 95 \% (табл. 1).

Сообщество с формулой 5С5С имеет 1 класс бонитета, сомкнутость крон 0,5. Возраст 50 и 120 лет соответственно породному составу. Древостой высотой от 19 до 25 м при диаметре стволов от 20 до 37 см. Подлесок достаточно густой, с сомкнутостью полога 25 \%, образован пятью видами из бореальной, боровой и сухих песков ЭЦГ. Проективное покрытие травяно-кустарничкового яруса составляет $40 \%$, растения которого представлены из следующих ЭЦГ: $\mathrm{Pn}-10, \mathrm{Br}-6, \mathrm{BrH}-1, \mathrm{Nm}-2, \mathrm{MDr}-2$, $\mathrm{MFr}-2, \mathrm{Kov}-3$. Мохово-лишайниковый ярус имеет проективное покрытие $90 \%$.

В сосняке с формулой $8 \mathrm{C} 2 \mathrm{C}$ древостой 2 класса бонитета, сомкнутость крон леса 0,5 , возраст от 113 до 80 лет. Высота P. sylvestris от 20 до 25 м, диаметр от 13,5 до 36 см. В первый ярус выходит также B. pendula высотой 18,5 м. Подлесок имеет сомкнутость полога 7 \%, образован Sorbus aucuparia L., J. communis, Ch. ruthenicus, Frangula alnus Mill. Проективное покрытие травяно-кустарничкового яру- 
Видовой состав одновозрастных и разновозрастных сосняков

\begin{tabular}{|c|c|c|c|c|c|}
\hline \multirow{2}{*}{ Название вида } & \multicolumn{5}{|c|}{ Формула леса } \\
\hline & $10 \mathrm{C}$ & 7C3C & $8 \mathrm{C} 2 \mathrm{C}$ & $5 \mathrm{C} 5 \mathrm{C}$ & $6 \mathrm{C} 4 \mathrm{C}$ \\
\hline \multicolumn{6}{|l|}{ Древостой (+ подрост) } \\
\hline Pinus sylvestris & + & + & + & + & + \\
\hline Picea $x$ fennica & + & + & + & + & + \\
\hline Betula pendula & + & + & + & + & + \\
\hline Quercus robur & + & & + & + & + \\
\hline Populus tremula & & & & & + \\
\hline \multicolumn{6}{|l|}{ Подлесок } \\
\hline Viburnum opulus & & & & + & \\
\hline Frangula alnus & + & 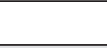 & + & + & + \\
\hline Juniperus communis & + & + & + & + & + \\
\hline Sorbus aucuparia & + & + & + & + & + \\
\hline Chamaecytisus ruthenicus & + & + & + & + & + \\
\hline Rubus idaeus & + & & & & \\
\hline \multicolumn{6}{|c|}{ Травяно-кустарничковый ярус (\%) } \\
\hline Astragalus arenarius & & & & & + \\
\hline Ledum palustre & + & 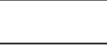 & & & \\
\hline Pimpinella saxifraga & & + & & & \\
\hline Vaccinium vitis-idaea & $10-40$ & 20 & 45 & 35 & 30 \\
\hline Centaurea sumensis & & + & & + & \\
\hline Calamagrostis epigeios & $5-15$ & 5 & 15 & 5 & 15 \\
\hline Calamagrostis arundinacea & 3 & 2 & 5 & 3 & 10 \\
\hline Veronica spicata & & + & & + & \\
\hline Veronica officinalis & & + & & & \\
\hline Pyrola chlorantha & & & & + & \\
\hline Fragaria vesca & + & + & + & 4 & \\
\hline Chimaphila umbellata & + & + & + & + & \\
\hline Dracocephalum ruyschiana & & & & + & \\
\hline Solidago virgaurea & + & + & + & + & + \\
\hline Chamaenerion angustifolium & + & & & 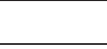 & + \\
\hline Gypsophila paniculata & & & & + & \\
\hline Campanula rotundifolia & + & + & & & + \\
\hline Rubus saxatilis & & & + & + & \\
\hline Antennaria dioica & & 1 & & + & 1 \\
\hline Polygonatum odoratum & & + & + & 2 & 2 \\
\hline Polygonatum multiflorum & & & & & + \\
\hline Convallaria majalis & + & 5 & + & + & 1 \\
\hline Linnaea borealis & + & & & & \\
\hline Platanthera bifolia & & 0,5 & & + & \\
\hline Ranunculus polyanthemos & & & & + & \\
\hline Melampyrum sylvaticum & + & + & & + & + \\
\hline Chamaedaphne calyculata & + & & & & \\
\hline Festuca valesiaca & & & & + & + \\
\hline Luzula pilosa & + & & + & & \\
\hline Orthilia secunda & & & + & + & + \\
\hline Carex ericetorum & + & + & & & + \\
\hline Carex omskiana & + & & & & \\
\hline Carex digitata & & & + & & + \\
\hline Hylotelephium triphyllum & & + & & & \\
\hline
\end{tabular}


Таблица 2 (окончание)

\begin{tabular}{|c|c|c|c|c|c|}
\hline \multirow{2}{*}{ Название вида } & \multicolumn{5}{|c|}{ Формула леса } \\
\hline & $10 \mathrm{C}$ & $7 \mathrm{C} 3 \mathrm{C}$ & $8 \mathrm{C} 2 \mathrm{C}$ & $5 \mathrm{C} 5 \mathrm{C}$ & $6 \mathrm{C} 4 \mathrm{C}$ \\
\hline Eremogone saxatilis & & & & & + \\
\hline Diphasiastrum complanatum & + & & + & & \\
\hline Hypopitys monotropa & + & + & & & \\
\hline Pulsatilla patens & + & + & + & + & + \\
\hline Eriophorum vaginatum & + & & & & \\
\hline Trientalis europaea & + & & + & & \\
\hline Silene nutans & & & & + & \\
\hline Silene viscosa & + & & & + & + \\
\hline Arctostaphylos uva-ursi & & + & & + & \\
\hline Trommsdorfia maculata & & + & & & \\
\hline Viola rupestris & + & + & + & & \\
\hline Vaccinium myrtillus & 20 & & 2 & + & \\
\hline Rumex acetosella & & + & & & + \\
\hline Dryopteris carthusiana & + & & & & + \\
\hline Dryopteris expansa & & & + & & \\
\hline Hieracium pilosella & + & + & & + & + \\
\hline Hieracium umbellatum & + & + & + & & + \\
\hline Hieracium echioides & & & & & + \\
\hline \multicolumn{6}{|c|}{ Мохово-лишайниковый ярус (\%) } \\
\hline Pleurozium schreberi & $20-65$ & 60 & 40 & 60 & 60 \\
\hline Dicranum scoparium & 20 & & 10 & 20 & 20 \\
\hline Dicranum polysetum & 10 & 25 & 9 & & \\
\hline Polytrichum juniperinum & 5 & & & & \\
\hline Hylocomium splendens & 5 & + & 1 & 5 & \\
\hline Sphagnum sp. & 5 & & & & \\
\hline Cladonia sylvatica & + & 5 & + & 2 & 3 \\
\hline Cladonia rangiferina & + & 5 & + & 3 & 2 \\
\hline
\end{tabular}

Примечание: серым цветом выделены ячейки с видами, встречающимися во всех сосняках.

са - 68\%, распределение видов по ЭЦГ следующее: $\mathrm{Pn}-6, \mathrm{Br}-6, \mathrm{BrH}$ - 2, Nm - 1, ExEd - 1, MDr - 3 . Мохово-лишайниковый ярус представлен 6 видами с общим проективным покрытием $60 \%$.

Сосняк с формулой 6 С 4 С имеет сомкнутость крон 0,4 , древостой 3 класса бонитета, возраст лесообразующей породы - от 113 до 73 лет, высота - от 22 до 27 м, диаметр - от 22 до 37 см. Сомкнутость полога подлеска составляет 15 \%. Общее проективное покрытие травяно-кустарничкового яруса - 60\%. Он сложен 23 видами (табл. 1), распределенными по следующим ЭЦГ: $\mathrm{Pn}-9, \mathrm{Br}-3, \mathrm{BrH}-2, \mathrm{Nm}-3$, $\mathrm{ExEd}-1, \mathrm{MDr}-1, \mathrm{MFr}-2, \mathrm{Kov}-2$. В нижнем ярусе встречаются зеленые мхи и лишайники с общим проективным покрытием $85 \%$.

Таким образом, видовое разнообразие исследованных сосняков невысокое: в целом, в возобновлении лесов участвуют 6 видов, подлесок представлен также 6 видами, травяно-кустарничковый ярус одновозрастных сосняков сложен 27 видами, разновозрастных - 48 видами в сумме (табл. 1). Тогда как для древостоя Медведского бора описано 27 видов растений, для подлеска - 23 вида, для травяно-кустарничкового яруса - 498 видов (Савиных и др., 2012). Это еще раз демонстрирует неоднородность территории памятника природы.

Общими для изученных боров, кроме основной лесообразующей породы, являются следующие виды: P. х fennica, B. pendula, S. aucuparia, J. communis, Ch. ruthenicus, V. vitis-idaea, C. epigeios, C. arundinacea (L.) Roth, Solidago virgaurea L., C. majalis, Pulsatilla patens (L.) Mill. (табл. 1). Присутствие J. communis, Ch. ruthenicus, P. patens, а также Astragalus arenarius L., Centaurea sumensis Kalen., Gypsophila paniculata L., Veronica spicata L., Eremogone saxatilis (L.) Ikonn. и др. подтверждает возмож- 
Распределение растений по эколого-ценотическим группам

\begin{tabular}{|c|c|c|c|}
\hline \multirow[b]{2}{*}{ Название группы } & \multicolumn{2}{|c|}{ Число видов } & \multirow[b]{2}{*}{ Примеры видов } \\
\hline & $10 \mathrm{C}$ & $\begin{array}{c}\text { СС (об- } \\
\text { щее) }\end{array}$ & \\
\hline Бореальная (Br) & 10 & 14 & $\begin{array}{l}\text { Sorbus aucuparia, Frangula alnus, Rubus saxatilis, } \\
\text { Melampyrum sylvaticum, Trientalis europaea, Pyrola } \\
\text { chlorantha, Linnaea borealis, Luzula pilosa и др. }\end{array}$ \\
\hline Боровая (Pn) & 10 & 22 & $\begin{array}{l}\text { Juniperus communis, Vaccinium vitis-idaea, Calamagros- } \\
\text { tis epigeios, Veronica officinalis, Chimaphila umbellata, } \\
\text { Campanula rotundifolia, Antennaria dioica и др. }\end{array}$ \\
\hline Неморальная (Nm) & 3 & 8 & $\begin{array}{l}\text { Polygonatum multiflorum, Convallaria majalis, } \\
\text { Platanthera bifolia, Carex digitata и др. }\end{array}$ \\
\hline Псаммофитно-травяная (PsTr) & 1 & 1 & Chamaecytisus ruthenicus \\
\hline Бореально-опушечная (BrH) & 4 & 3 & $\begin{array}{l}\text { Rubus idaeus, Calamagrostis arundinacea, Solidago } \\
\text { virgaurea, Chamaenerion angustifolium }\end{array}$ \\
\hline Неморально-опушечная (ExEd) & 1 & 1 & Hieracium umbellatum \\
\hline Сухих лугов (MDr) & 1 & 4 & Rumex acetosella и др. \\
\hline Влажно-луговая (MFr) & 0 & 2 & Fragaria vesca, Ranunculus polyanthemos \\
\hline Ковыльниковая (Kov) & 0 & 4 & Gypsophila paniculata, Festuca valesiaca, Silene viscosa \\
\hline Олиготрофная (Olg) & 3 & 0 & $\begin{array}{l}\text { Ledum palustre, Chamaedaphne calyculata, } \\
\text { Eriophorum vaginatum }\end{array}$ \\
\hline Водно-болотная (Wt) & 1 & 0 & Carex omskiana \\
\hline
\end{tabular}

ность наличия в прошлом на территории памятника природы более сухих боров и становление на их месте сосняков с типичными боровыми и бореальными видами. В то же время наличие типичных бореальных видов (табл. 1, 2) указывает на трансформацию боровых сообществ Медведского бора в темнохвойные леса. Вероятно, в этом причина исчезновения с территории памятника природы Stipa pennata L., Helichrisum arenarium (L.) Moench, малочисленность ценопопуляций степных и лесостепных видов растений.

Флора одновозрастных (с формулой 10С) и разновозрастных (СС) сосняков распределена по 9 ЭЦГ. Преобладают по числу видов бореальная и боровая ЭЦГ, при этом во второй группе лесов растений боровой ЭЦГ в 2,2 раза больше по сравнению с первой. По-видимому, своевременная лесохозяйственная деятельность способствует поддержанию сосняков со своим набором видов. Значительное число видов бореальной ЭЦГ обусловлено расположением Кировской области в таежной зоне и преобладанием темнохвойных (еловых, елово-пихтовых, пихтово-еловых) лесов. В отличие от одновозрастных сосняков в разновозрастных появляются влажно-луговая и лугово-степная ЭЦГ. Наличие лугово-степной ЭЦГ также связано с «открытием» участков при лесохозяйственной деятельности. В борах с формулой $10 \mathrm{C}$ присутствуют олиготрофная и водно-болотная ЭЦГ, растения которых произрастают во влажных и заболоченных местах.

Таким образом, спектр ЭЦГ сосняков свидетельствует о длительной истории формировании флоры ПП «Медведский бор». В одновозрастных сообществах наблюдается формирование подроста и подлеска из бореальных видов, увеличение полноты насаждений и, как следствие, упрощение структуры и уменьшение видового разнообразия травяно-кустарничкового яруса. В разновозрастных сосняках сохраняется высокое видовое разнообразие за счет «оконной» структуры леса, когда осветление подполового яруса позволяет произрастать видам разных ЭЦГ. Данные исследования могут служить основой для наблюдений и прогноза дальнейших преобразований сосняков.

\section{ЛИТЕРАТУРА}

Киселёва Т. М., Пересторонина О. Н., Савиных Н. П. Роль ООПТ «Медведский бор» в сохранении $\alpha, \beta$ и $\gamma$ разнообразия на территории Кировской области // Роль заповедников лесной зоны в сохранении и изучении био- 
логического разнообразия Европейской части России: материалы науч.-практ. конф., посвящ. 70-летию Окского государственного природного биосферного заповедника. Сер. «Труды Окского государственного природного биосферного заповедника». - Рязань, 2005. - Вып. 24. - С. 403-412.

Оценка и сохранение биоразнообразия лесного покрова в заповедниках Европейской России / под ред. Л. Б. Заугольновой. - М.: Научный мир, 2000. - 185 с.

Пересторонина О. Н., Савиных Н. П., Гальвас А. Г., Зыкин А. Е. Динамика биоразнообразия лесов на охраняемых территориях (на примере памятника природы «Медведский бор») // Сохранение лесных экосистем: проблемы и пути их решения: материалы Всеросс. науч.-практ. конф. (г. Киров, 15-19 мая 2017 г.). - Киров: ООО «Изд-во «Радуга-ПРЕСС», 2017. - С. 81-87. $530 \mathrm{c}$

Полевая геоботаника / под общ. ред. Е. М. Лавренко и А. А. Корчагина. - Л.: Изд-во «Наука», 1964. - Т. III. -

Полевая геоботаника / под общ. ред. Е. М. Лавренко и А. А. Корчагина. - Л.: Изд-во «Наука», 1972. - T. IV. $336 \mathrm{c}$.

Савиных Н. П., Киселева Т. М., Пересторонина О. Н., Копысов В. А., Шабалкина С. В., Пичугина Е. В. Жемчужина Вятского края - Медведский бор // Медведский бор. - Киров: Триада плюс, 2006. - С. 81-95.

Савиных Н. П., Пересторонина О. Н., Киселева Т. М. Состояние и возобновление сосновых лесов ООПТ «Медведский бор» // Известия Самарского научного центра Российской академии наук, 2012. - Т. 14, № 15. - С. $1359-1362$.

Соловъев А. Н. Сокровища вятской природы. - Киров: Волго-Вятск. кн. изд-во, 1986. - 159 с. 